\title{
Lack of association of rare functional variants in TSC1/TSC2 genes with autism spectrum disorder
}

Samira Bahl' ${ }^{1}$, Colby Chiang ${ }^{1}$, Roberta L Beauchamp ${ }^{1}$, Benjamin M Neale ${ }^{1,2,3}$, Mark J Daly ${ }^{1,2,3}$, James F Gusella $a^{1,3,4}$, Michael E Talkowski ${ }^{1,3}$ and Vijaya Ramesh ${ }^{1 *}$

\begin{abstract}
Background: Autism spectrum disorder (ASD) is reported in 30 to $60 \%$ of patients with tuberous sclerosis complex (TSC) but shared genetic mechanisms that exist between TSC-associated ASD and idiopathic ASD have yet to be determined. Through the small G-protein Rheb, the TSC proteins, hamartin and tuberin, negatively regulate mammalian target of rapamycin complex 1 (mTORC1) signaling. It is well established that MTORC1 plays a pivotal role in neuronal translation and connectivity, so dysregulation of MTORC1 signaling could be a common feature in many ASDs. Pam, an E3 ubiquitin ligase, binds to TSC proteins and regulates mTORC1 signaling in the CNS, and the FBXO45-Pam ubiquitin ligase complex plays an essential role in neurodevelopment by regulating synapse formation and growth. Since mounting evidence has established autism as a disorder of the synapses, we tested whether rare genetic variants in TSC1, TSC2, MYCBP2, RHEB and FBXO45, genes that regulate mTORC1 signaling and/or play a role in synapse development and function, contribute to the pathogenesis of idiopathic ASD.

Methods: EXons and splice junctions of TSC1, TSC2, MYCBP2, RHEB and FBXO45 were resequenced for 300 ASD trios from the Simons Simplex Collection (SSC) using a pooled PCR amplification and next-generation sequencing strategy, targeted to the discovery of deleterious coding variation. These detected, potentially functional, variants were confirmed by Sanger sequencing of the individual samples comprising the pools in which they were identified.

Results: We identified a total of 23 missense variants in MYCBP2, TSC1 and TSC2. These variants exhibited a near equal distribution between the proband and parental pools, with no statistical excess in ASD cases $(P>0.05)$. All proband variants were inherited. No putative deleterious variants were confirmed in RHEB and FBXO45. Three intronic variants, identified as potential splice defects in MYCBP2 did not show aberrant splicing upon RNA assay. Overall, we did not find an over-representation of ASD causal variants in the genes studied to support them as contributors to autism susceptibility.
\end{abstract}

Conclusions: We did not observe an enrichment of rare functional variants in TSC1 and TSC2 genes in our sample set of 300 trios.

Keywords: Autism spectrum disorder, Tuberous sclerosis complex, Mammalian target of rapamycin, Next-generation sequencing, Rare variants

\section{Background}

Autism spectrum disorders (ASDs) are a heterogeneous group of neurodevelopmental disorders characterized by impairments in reciprocal social communication and stereotyped behaviors. Though the genetic causes of ASD are diverse [1], mutations in many ASD genes, including

\footnotetext{
* Correspondence: ramesh@helix.mgh.harvard.edu

${ }^{1}$ Center for Human Genetic Research, Massachusetts General Hospital, Boston, MA 02114, USA

Full list of author information is available at the end of the article
}

NRXN1, NLGN3/4 and SHANK2/3, are associated with altered synaptogenesis, establishing aberrant synaptic protein synthesis and/or synaptic function as a common underlying mechanism in ASD [2,3]. Single gene Mendelian disorders such as tuberous sclerosis complex (TSC), fragile X syndrome (FXS), Rett's syndrome and Angelman syndrome show a high prevalence of autism [4]. An understanding of the underlying mechanisms of autism in such single gene disorders may offer insights into the pathogenesis of idiopathic ASD. TSC, characterized by

\section{Biomed Central}

(c) 2013 Bahl et al.; licensee BioMed Central Ltd. This is an Open Access article distributed under the terms of the Creative Commons Attribution License (http://creativecommons.org/licenses/by/2.0), which permits unrestricted use, distribution, and reproduction in any medium, provided the original work is properly cited. 
benign hamartomas in multiple organs, is caused by mutations in either of the two tumor suppressor genes encoding hamartin (TSC1) and tuberin (TSC2). Features of ASD are present in 30 to $60 \%$ of individuals with TSC [5]. Hamartin and tuberin form a complex that functions as a critical negative regulator of mammalian target of rapamycin complex 1 (mTORC1)-mediated signaling [6,7].

The TSC proteins act as a central hub in relaying signals from diverse cellular pathways to control mTORC1 activity (Figure 1). mTORC1 signaling in neuronal translation has been established as a regulator of longlasting synaptic plasticity and memory as it integrates signals from many neuronal surface receptors/channels via ERK- and PI3K/Akt-mediated phosphorylation of the TSC1-TSC2 complex. Translational control is also essential for neuronal functions such as growth and axon guidance [8]. Furthermore, aberrant activation of mTORC1 signaling is a common feature in syndromes associated with autistic phenotypes and cognitive impairments such as TSC, fragile-X, neurofibromatosis-1 (NF1) as well as those with PTEN mutations seen in ASD with macrocephaly [9].
Consequently, we hypothesized that aberrant mTORC1 signaling may be a shared pathway between syndromic ASD and non-syndromic ASD, and that rare functional variants in genes that regulate mTORC1 signaling and/or play a role in synapse development and function may be associated with ASD. In this study, we chose TSC1, TSC2, $M Y C B P 2, R H E B$ and $F B X O 45$ as candidate genes for nonsyndromic ASD and carried out resequencing in 300 ASD trios from the Simons Simplex Collection (SSC) using nextgeneration sequencing (NGS) technology. The rationale for the selection of these genes is based on their critical roles in neurodevelopment as briefly described below.

Loss of a single copy of Tsc1 in the mouse results in defects in neuronal morphology, including increased soma size, decreased spine density and increased spine size, thus implicating TSC proteins in synapse function in neurons [10]. Mice with a heterozygous inactivating mutation in Tsc2 exhibit abnormal hippocampal CA1 long-term potentiation (LTP), and consequently deficits in hippocampal-dependent learning [11]. Treatment with rapamycin, a specific inhibitor of mTORC1 can improve neuronal hypertrophy and improve behavioral

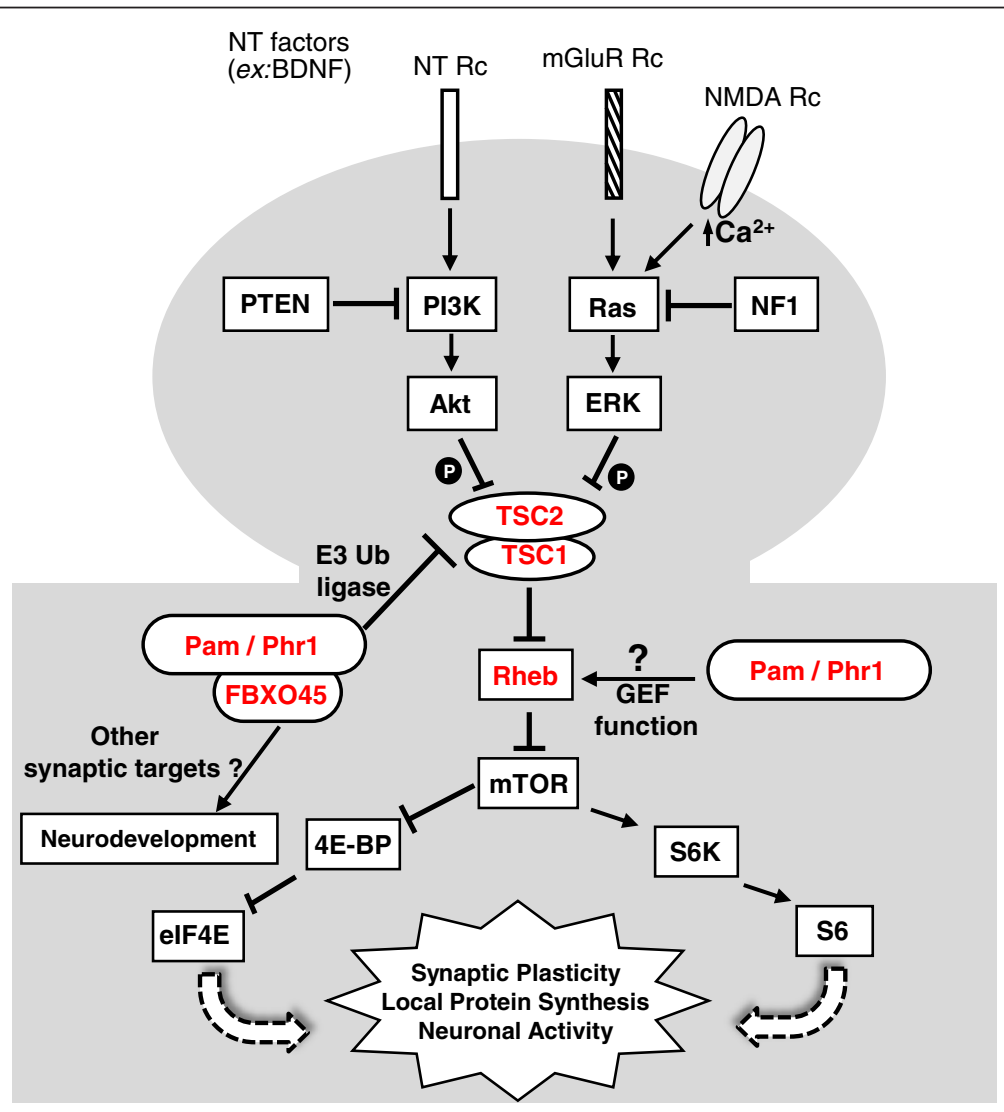

Figure $1 \mathrm{~A}$ model of TSC/mTORC1 signaling pathway at the neuronal synapse. Tuberin (TSC2) and hamartin (TSC1) act as central players in mTORC1 signaling to regulate neuronal/synaptic activity. Neurotrophic (NT) factors such as BDNF, as well as synaptic activity initiate mTORC1 signaling via receptors (Rc) including neurotrophic Rc and glutamate receptors including NMDA Rc and mGluR Rc. The mTOR candidate genes resequenced in the study are shown in red. Ub, ubiquitin; P, phosphorylation. 
phenotypes in $T s c 2^{+/-}$mutant mice [11]. Recent studies report rare variants in TSC1 and TSC2 genes to be associated with idiopathic ASD [12,13].

The small GTPase Rheb (Ras homology enriched in brain) is a direct target of tuberin and hamartin in both Drosophila and mammals [14,15]. Rheb is highly expressed in the hippocampus and is rapidly induced by growth factors and receptor-dependent synaptic activity, suggesting that Rheb may play an essential role in long term activitydependent neuronal response [16]. We hypothesized that gain of function mutations in $R H E B$, resulting in aberrant mTORC1 activation and synaptic connectivity may occur in ASD.

We previously identified Pam $(M Y C B P 2)$ as an interactor of the TSC protein complex in the mammalian CNS [17]. Human Pam and its homologs (the PHR family of proteins), including Phr1 in mouse, Highwire (HIW) in Drosophila, Regulator of Presynaptic Morphology (RPM-1) in Caenorhabditis elegans, and Esrom in zebrafish, are E3 ubiquitin ligases that have emerged as key regulators of axon guidance, outgrowth and synapse development [18]. Our studies show that Pam interacts with the TSC1-TSC2 complex, and regulates mTORC1 signaling [17,19,20]. FBXO45, an F-box protein restricted to the nervous system, is required for normal neuromuscular synaptogenesis, axon pathfinding and neuronal migration. Proteomic analysis has revealed that FBXO45 specifically associates with Pam, forming a novel FBXO45-Pam ubiquitin ligase complex that plays an important role in neural development [21].

\section{Methods}

\section{ASD subjects}

We obtained lymphoblast cell line DNA samples from 300 ASD trios through the Simons Simplex Collection (SSC), a resource of the Simons Foundation Autism Research Initiative (SFARI) [22]. DNAs from the deidentified subjects used in this study were obtained, with the institutional review board approval of Partners HealthCare System, from the Rutgers University Cell and DNA Repository. DNAs and cell lines deposited into this public repository, to further ASD research as part of the SSC, were all from affected subjects and unaffected family members who provided informed consent through the SFARI and its twelve participating institutions (Baylor College of Medicine, Children's Hospital Boston, Columbia University, Emory University, McGill University, University of California, Los Angeles, University of Illinois at Chicago, University of Michigan, University of Missouri, University of Washington, Vanderbilt University and Yale University), based upon protocols approved by each institutional review board. The SSC families included in the study are provided in Additional file 1: Table S1.

\section{Next-generation sequencing}

\section{Genomic DNA pooling strategy}

DNA concentration was measured by Quant-iT ${ }^{\mathrm{TM}}$ PicoGreen ${ }^{\circledR}$ dsDNA reagent (Invitrogen, Carlsbad, CA, USA) and normalized to $4 \mathrm{ng} / \mu \mathrm{L}$ by multiple rounds of quantification and dilution. A $10 \%$ variance was allowed, as that is the limit of quantitation of PicoGreen ${ }^{\circledR}$ detection system [23]. A pooling strategy was employed to process the $300 \mathrm{SSC}$ trios wherein 10 pools of probands (30 samples per pool), and 10 pools of parents (60 samples per pool comprising 30 mothers and 30 fathers for each corresponding proband) were assembled (Additional file 2: Figure S1). Samples were pooled after multiple rounds of quantification and normalization, as described earlier [23], to ensure that the DNA pool accurately reflected sample allele frequency. No other experiments were performed to examine the sample coverage directly.

\section{Target amplification and PCR pools}

Primers were designed for all coding exons of TSC1, TSC2, MYCBP2, RHEB and FBXO45 using Primer3 software on the hg19 reference sequence (amplicons of 200 to 600 base pairs (bp) including approximately 100 bp of intronic sequence flanking either side of each exon; exons exceeding $600 \mathrm{bp}$ were split into two or more overlapping amplicons). All amplicons were tested on three HapMap CEPH (CEU) samples. To provide a recognition site for downstream concatenation, NotI tails (5' CGCGTTGCGGCCGC 3') were added to the primer ends. The details of the primers designed for the five genes are provided in Additional file 3: Table S2. Target regions were PCR amplified using PfuLltra II $^{\mathrm{TM}}$ Fusion HS DNA polymerase (Agilent Technologies, Santa Clara, CA, USA) for all the 20 DNA pools assembled. Following amplification, a representative subset of PCR amplicons (for each DNA pool) was visualized by agarose gel electrophoresis for confirmation/quality control. The PCR amplification products were again quantified by PicoGreen ${ }^{\circledR}$, normalized and pooled, yielding PCR pools containing equal concentrations of PCR amplicons from all exons of each candidate gene.

\section{Library preparation and high throughput sequencing}

As described by Calvo et al. [24], products were concatenated following amplification, size selected (> $600 \mathrm{bp}$ ), and randomly sheared using a Covaris S2 system (Covaris, Inc., Woburn, MA, USA) into fragments ranging from 150 to $200 \mathrm{bp}$ in length. Following Illumina paired-end library preparation of the sheared products (Illumina, San Diego, CA, USA), the final libraries were quantified by PicoGreen ${ }^{\circledR}$ (Quant-iT, Invitrogen, Carlsbad, CA, USA), Agilent Bioanalyzer DNA 1000 kit (Agilent Technologies, Santa Clara, CA, USA), and Quantitative PCR (qPCR) analysis with iQ SYBR Green 
Supermix (Bio-Rad Laboratories, Hercules, CA, USA). qPCR was performed with primers targeting the Illumina adaptor oligos and an Illumina PhiX sample serially diluted for a standard curve, thereby quantifying only DNA fragments containing properly ligated adaptor oligos required for sequencing. For additional quality control, some of the libraries were cloned into a sequencing vector using Zero Blunt ${ }^{\circledR}$ TOPO $^{\circledR}$ PCR Cloning Kit (Invitrogen, Carlsbad, CA, USA), and representative individual clones were sequenced (using conventional Sanger method) to verify the presence of candidate gene exons within the libraries. 76 bp reads were aligned to the genome using Novoalign (Novocraft, Selangor, Malaysia) and mutation analysis was performed with the Genome Analysis Toolkit [25,26] and Syzygy [23].

\section{Confirmation of identified variants}

Confirmation of the potentially deleterious variants identified was performed by Sanger sequencing on an ABI 3730 capillary sequencer and DNA sequence analysis was performed using Sequence Scanner software version 1.0 (Applied Biosystems, Foster City, CA, USA). PCR primers used for sequencing were the same as those used for amplification of exons from sample pools except for the NotI tails. We also tested all the confirmed proband variants in the corresponding parental pools and all the confirmed parental variants in the corresponding proband pools.

\section{Variant analyses}

The significance of differences in the number of variants occurring between ASD cases and parents was tested using Fisher's exact test, with nominal statistical significance defined as a two-sided $P<0.05$. The potential consequence on protein function of each confirmed missense variant was evaluated using PolyPhen-2 software [27]. The branch point sequence analysis module of the Human Splicing Finder Version 2.4.1 was used to identify potential splicing defects [28]. Default settings were used for all prediction programs.

\section{Testing intronic variants for exon skipping}

Total RNA was isolated using RNeasy Mini kit (Qiagen Sciences, Germantown, MD, USA) according to the manufacturer's instructions. RNA quantity and quality were measured by ND-1000 (Nanodrop, Thermo Scientific, Lafayette, Co, USA). First strand cDNA was generated using SuperScript ${ }^{\mathrm{TM}}$ II reverse transcriptase according to the manufacturer's instructions (Invitrogen, Carlsbad, CA, USA). MYCBP2 intronic variants were tested for exon skipping using the following cDNA primer pairs: (a) 5' ACCACAGCATGACAGCCATA 3' and 5' GCAAGTCCTTTTCCAGATCG 3' for variant c.162519T>C, (b) 5' TGGCAGCTATGCAGGACTTA 3' and 5' TGCAAGAAGGTCACCATCAG 3' for variant c.3982
$+31 \mathrm{C}>\mathrm{G}$ and (c) 5' TTCATTGGAGACTGCATCAGA 3' and 5' TGCAGCCTCCTCAAGAATTT 3' for variant c.6727-16T $>$ C.

\section{Results}

We sequenced the coding regions of five candidate genes that regulate mTORC1 signaling and/or are implicated in synapse development and function (TSC1, TSC2, MYCBP2, RHEB and FBXO45) in 300 ASD trios from the SSC. We combined DNA from the 300 trios into 10 pools of $30 \mathrm{ASD}$ probands and 10 pools of the corresponding 60 parents (Additional file 2: Figure S1). Each pool was PCR amplified to capture the 155 coding exons from the five target genes (Table 1). RHEB exon 1 and the first 125 bases of FBXO45 exon 1 could not be successfully amplified and hence are not included in the study. The 165 successful PCR amplicons were combined, concatenated and sheared to construct libraries. The 20 libraries were sequenced using the Illumina Genome Analyzer (Illumina, San Diego, CA, USA).

Sequencing yielded relatively uniform coverage distribution of each exon across all five candidate genes and 20 pools. A representative example of the uniform sequencing coverage obtained is depicted in Figure 2 for two of the largest genes sequenced, $M Y C B P 2$ (83 coding exons) and TSC2 (41 coding exons) for two proband pools and their corresponding parental pools. For all coding exons, read depth averaged at least $15,000 \mathrm{x}$ for each pool, or $200 \mathrm{x}$ for each individual proband/parent sample. Overall, sequence coverage was obtained from $99.4 \%$ of all targeted exons and $99.8 \%$ of all targeted bases (Table 1). Additional file 4: Table S3 provides the mean and range of sequence coverage over each exon for the five genes examined, with data for each proband and parental pool shown separately. Also, we were able to detect and confirm one variant in a pool of 30 samples (3.33\% sensitive) and one variant in a pool of 60 samples (1.66\% sensitive) by the analytical tools used.

After filtering for high quality variant calls using Syzygy [23], the variants were classified for analysis by (1) type/location, into nonsense, coding non-synonymous (missense), coding synonymous, intronic, 3'-UTR, 5'-UTR, and 5'- and 3'- splice variants, (2) distribution, into proband (proband pool only), 'inherited' (proband and corresponding parental pool) and non-transmitted (parental pool only) variants, and (3) presence/absence in either the dbSNP or 1000 Genomes databases, into reported and novel variants. We prioritized those proband, inherited or parental coding variants, not previously reported in the public databases that produced a premature stop codon (nonsense) or other non-synonymous change, as well as intronic variants that had a potential role in altering splicing based upon branch point sequence analysis (see Methods). The selected variants were confirmed by Sanger di-deoxy sequencing of 
Table 1 Coverage summary of mTOR pathway candidate genes sequenced by next generation sequencing

\begin{tabular}{cccccccc}
\hline Gene & Chromosome & Exons screened & $\begin{array}{c}\text { Targeted } \\
\text { exon bases }\end{array}$ & $\begin{array}{c}\text { High coverage } \\
\text { bases }^{\mathbf{a}}\end{array}$ & $\begin{array}{c}\text { Average coverage } \\
\text { per pool }\end{array}$ & $\begin{array}{c}\text { Average coverage } \\
\text { per proband }^{\mathbf{b}}\end{array}$ & $\begin{array}{c}\text { Average coverage } \\
\text { per parent }^{\mathbf{b}}\end{array}$ \\
\hline TSC1 & 9 & Exons 3-23 & 3495 & 3495 & 52804.6 & 1760.2 & 880.1 \\
\hline TSC2 & 16 & Exons 1-41 & 5355 & 5355 & 79732.3 & 2657.7 & 1328.9 \\
\hline RHEB & 7 & Exons 2-8 & 555 & 503 & 16050.2 & 535 & 267.5 \\
\hline MYCBP2 (Pam) & 13 & Exons 1-83 & 13923 & 13923 & 21906.8 & 730.2 & 365.1 \\
\hline FBXO45 & 3 & Exons 1-3 & 861 & 858 & 33853.7 & 1128.5 & 564.2 \\
\hline
\end{tabular}

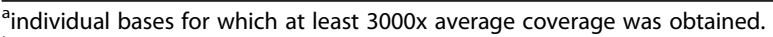

${ }^{b}$ statistics reflect coverage per proband/parent sample, not per chromosome.

individual DNA samples comprising the pool(s) in which the variant was identified.

Notably, there were no confirmed de novo events in the probands or inherited nonsense variants in any of the five genes. A total of ten missense and three non-coding intronic variants in $M Y C B P 2$, three missense variants in TSC1 and ten missense variants in TSC2 were confirmed. There were no confirmed variants of interest based on the above criteria in FBXO45 and RHEB. A recent study, which examined the metabotropic glutamate-receptor (mGluR) signaling pathway genes for rare genetic variants contributing to autism susceptibility also, did not find any significant coding variants in RHEB [12].

Of the ten missense variants confirmed in $M Y C B P 2$, four (K1325R, I1581V, D2437N and N2811D) were observed as variants inherited by the proband from a parent. The remaining six variants (V534I, K543R, V1285I, F1849C, P2533L and $\mathrm{R} 2803 \mathrm{H}$ ) were identified in different parent
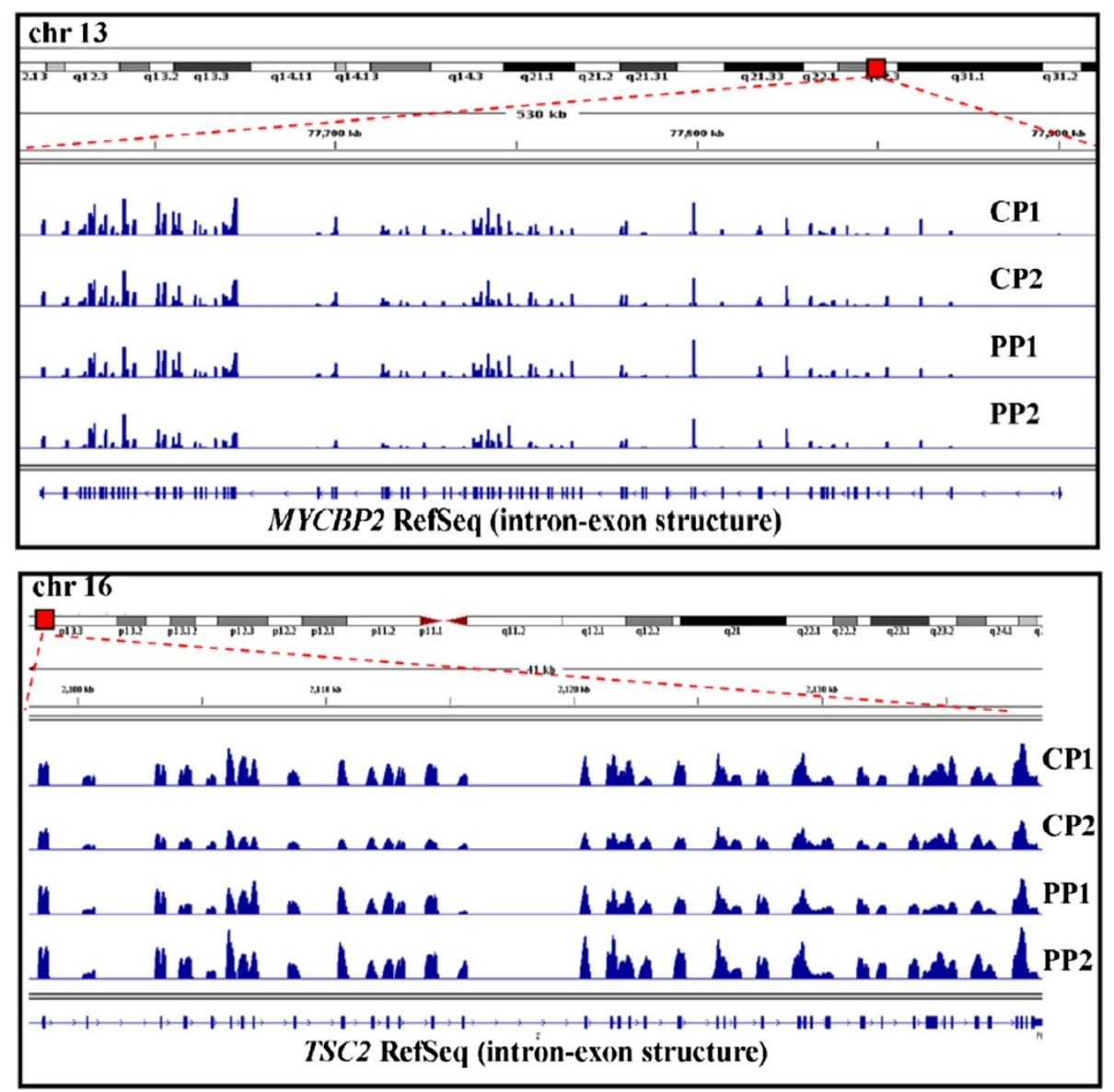

Figure 2 Schematic representation of the sequence coverage data. Coverage plots, represented by blue peaks, are shown for two of the largest genes studied, MYCBP2 (83 exons, upper panel) and TSC2 (41 exons, lower panel). Intron-exon structure of the genes is shown along with sequencing coverage for each exon for proband pools 1 and 2 (PP1, PP2) and their corresponding parental pools (CP1, CP2). The coverage plots were generated using The Integrative Genomics Viewer at Broad Institute [29]. 
samples as singletons, not transmitted to the proband. The inherited variant K1325R and non-transmitted variant V534I were both found in the father of a single trio (Table 2). The three intronic variants (c.1625-19T $>C$, c. $3982+31 \mathrm{C}>\mathrm{G}$ and c.6727-16T $>\mathrm{C}$ ) confirmed in $M Y C B P 2$ were all inherited (Table 2). None occurred at a classic donor/acceptor site but they were suspected instead to represent potential splicing defects due to their occurrence at putative branch/polypyrimidine sites. However, no exon skipping was observed for any of the three variants when the respective RNA samples were analyzed (data not shown).

For the TSC genes, we confirmed two inherited missense variants (T360N and P448S) in TSC1 and six (I64V, H152D, K533Q, K954R, E984Q and A1429S) in TSC2. Four of these (TSC1: T360N, P448S; TSC2: $\mathrm{K} 533 \mathrm{Q}, \mathrm{Q} 984 \mathrm{~N})$ have been previously reported as potential risk factors for ASD [12,13]. We also identified one nontransmitted parental missense variant (L116V) in TSC1 and four (C728F, P878S, S960F and T1330M) in TSC2 (Table 3). Two independent studies have reported differing roles for the TSC1 L116V variant, as an ASD specific variant [12] and as a control variant [13], though it appears here to be a rare polymorphism (Table 3). All the three TSC1 variants (inherited variants $\mathrm{T} 360 \mathrm{~N}$ and $\mathrm{P} 448 \mathrm{~S}$, and non-transmitted variant $\mathrm{L} 116 \mathrm{~V}$ ) are also reported in the tuberous sclerosis database - Leiden Open Variation Database (LOVD, http:// chromium.liacs.nl/LOVD2/TSC/home.php) - as probably non-pathogenic. However, all the TSC2 variants excepting,
A1429S and T1330M are novel (Table 3). The variants T360N in TSC1 and A1429S in TSC2 were detected in both parents; however, the respective probands were heterozygous for these changes (Table 3).

As an additional large scale control dataset, we used data from the National Heart, Lung, and Blood Institute exome variant server (NHLBI EVS) and found five variants in MYCBP2 (V534I, K543R, V1285I, R2803H and N2811D), all three TSC1 variants (L116V, T360N and P448S) and a single TSC2 variant (A1429S) to be reported in the controls (Tables 2 and 3).

Overall, we did not find a significant enrichment of rare inherited variants in ASD probands as compared to the non-transmitted variants in parents for $M Y C B P 2$ $(P>0.05)$ or the TSC genes $(P>0.05)$.

An additional review of TSC missense mutations reported in LOVD with NHLBI EVS suggested that 19 TSC1 and 56 TSC2 variants were seen in controls. Furthermore, missense variants in TSC genes reported to have functional impact [30-32] were catalogued and found not to be seen in idiopathic ASD cases, suggesting that mutations observed in frank TSC are not seen in ASD (Additional file 5: Table S4).

\section{Discussion}

Dysregulation of mTORC1 signaling is correlated with aberrant synaptic protein synthesis and has emerged as a common biochemical pathway in many syndromes associated with ASD. Because approximately 50 to $60 \%$

Table 2 Details of rare variants identified in MYCBP2 in ASD cases and parents

\begin{tabular}{|c|c|c|c|c|c|c|}
\hline SSC Proband/ Parent ID ${ }^{a}$ & Variant type & Coordinate $^{b}$ & Amino acid position ${ }^{c}$ & Inheritance & $\begin{array}{l}\text { Functional prediction } \\
\text { by polyphen-2 }\end{array}$ & $\begin{array}{c}\text { Exome variant } \\
\text { server }^{d}\end{array}$ \\
\hline \multicolumn{7}{|c|}{ Inherited coding sequence variants } \\
\hline 11664.p1 & missense & 77764453 & K1325R & paternal & damaging & - \\
\hline 11441.p1 & missense & 77755922 & I1581V & maternal & benign & - \\
\hline 11002.p1 & missense & 77714277 & $\mathrm{D} 2437 \mathrm{~N}$ & maternal & damaging & - \\
\hline 11000.p1 & missense & 77672744 & N2811D & maternal & benign & reported \\
\hline \multicolumn{7}{|c|}{ Non-transmitted coding sequence variants } \\
\hline 11664.fa & missense & 77835444 & V534I & - & benign & reported \\
\hline $11587 . \mathrm{fa}$ & missense & 77835416 & K543R & - & benign & reported \\
\hline 11573.mo & missense & 77765917 & V1285I & - & benign & reported \\
\hline 11149.fa & missense & 77745761 & F1849C & - & benign & - \\
\hline 11765.mo & missense & 77700625 & P2533L & - & benign & - \\
\hline 11775.mo & missense & 77672767 & $\mathrm{R} 2803 \mathrm{H}$ & - & benign & reported \\
\hline \multicolumn{7}{|c|}{ Intronic variants (potential splicing defects) } \\
\hline 11242.p1 & c.1625-19T>C & 77838156 & - & paternal & - & - \\
\hline 11417.p1 & c.3982+31C>G & 77779577 & - & maternal & - & - \\
\hline 11291.p1 & c.6727-16Т>C & 77738691 & - & maternal & - & - \\
\hline
\end{tabular}

ap1: proband; fa: father, mo: mother.

${ }^{b}$ coordinates based on genome build hg19.

camino acid position based on Swiss-Prot accession \# 075592.3.

${ }^{d} \mathrm{NHLBI}$ exome variant server, Seattle, WA, USA. 
Table 3 Details of rare missense variants identified in TSC genes in ASD cases and parents

\begin{tabular}{|c|c|c|c|c|c|c|c|}
\hline TSC gene & $\begin{array}{l}\text { SSC Proband/ } \\
\text { Parent ID }^{\mathrm{a}}\end{array}$ & Coordinate $^{b}$ & $\begin{array}{l}\text { Amino acid } \\
\text { positionc }^{c}\end{array}$ & Inheritance & $\begin{array}{l}\text { Functional prediction } \\
\text { by polyphen-2 }\end{array}$ & LOVD TSC database $^{d}$ & $\begin{array}{c}\text { Exome variant } \\
\text { server }^{\mathrm{e}}\end{array}$ \\
\hline \multicolumn{8}{|c|}{ Inherited coding sequence variants } \\
\hline TSC1 & 11208.p1 & 135786451 & $\mathrm{~T} 360 \mathrm{~N}$ & both & damaging & probably not pathogenic & reported $(0.0461)$ \\
\hline TSC1 & 11409.p1 & 135782214 & P448S & paternal & benign & probably not pathogenic & reported $(0.3844)$ \\
\hline TSC2 & 11232.p1 & 2100452 & $164 \mathrm{~V}$ & paternal & damaging & - & - \\
\hline TSC2 & 11443.p1 & 2104414 & $\mathrm{H} 152 \mathrm{D}$ & maternal & benign & - & - \\
\hline TSC2 & 11543.p1 & 2114426 & K533Q & maternal & damaging & - & - \\
\hline TSC2 & 11619.p1 & 2127622 & K954R & paternal & benign & - & - \\
\hline TSC2 & 11590.p1 & 2127711 & E984Q & paternal & damaging & - & - \\
\hline TSC2 & 11196.p1 & 2134508 & A1429S & both & benign & no known pathogenicity & reported $(0.2324)$ \\
\hline \multicolumn{8}{|c|}{ Non-transmitted coding sequence variants } \\
\hline${ }^{f} \mathrm{TSCl}$ & - & 135800991 & L116V & - & damaging & pathogenicity unknown & reported $(0.0154)$ \\
\hline TSC2 & 11780.fa & 2122327 & $\mathrm{C} 728 \mathrm{~F}$ & - & damaging & - & - \\
\hline TSC2 & 11458.mo & 2125886 & P878S & - & damaging & - & - \\
\hline TSC2 & 11303.mo & 2127640 & S960F & - & damaging & - & - \\
\hline TSC2 & 11195.mo & 2133801 & T1330M & - & benign & pathogenicity unknown & - \\
\hline
\end{tabular}

ap1: proband; fa: father; mo: mother.

${ }^{\mathrm{b}}$ coordinates based on genome build hg19.

camino acid position based on Swiss-Prot accession \# Q92574.2 and P49815.2 for TSC1 and TSC2, respectively.

${ }^{d}$ tuberous sclerosis database: Leiden Open Variation Database.

${ }^{\text {e }} \mathrm{NHLBI}$ exome variant server, Seattle, WA, USA. Values in parentheses denote minor allele frequency in percent.

fidentified by next-generation sequencing but not tested by Sanger sequencing because it was previously reported.

of TSC patients exhibit autistic phenotypes, we hypothesized that functional rare variants in genes that regulate mTORC1 signaling may be frequent in non-syndromic ASD, which may explain the autistic phenotypes shared between TSC and ASD in general. We investigated five mTOR pathway candidates, TSC1, TSC2, MYCBP2, RHEB and FBXO45, based upon their critical roles in neurodevelopment. Mice lacking these genes exhibit defects in synapse development, axon navigation and hippocampal-dependent learning [20,21,33-35]. The findings of our study however do not support the hypothesis and suggest that rare variants in the studied mTOR pathway candidate genes do not play a significant causal role in autism. We did not detect support for a genetic association between any of the studied genes and autism. No de novo variations, considered to be a hallmark of the risk-determining genes of greatest effect, were identified; neither did we identify any nonsense variants. In $M Y C B P 2$, TSC1 and TSC2, we observed a few rare inherited single nucleotide variants in ASD probands, but a comparable number of variants were also found in the parents indicating that the ASD variants are probably rare private sequence changes.

Next-generation sequencing of pooled samples is shown to be efficient and cost-effective in capturing variation in a limited target region that has been selectively amplified in multiple DNA samples as shown in studies to identify genes in type 1 diabetes, human complex 1 deficiency and inflammatory bowel diseases $[23,24,36]$. The approach is capable of deriving very deep coverage in targeted regions and as such can be sensitive to the detection of rare or private events within the pool [24]. However, it should be noted that we chose to validate only the subset of presumably deleterious and thus potentially pathogenic variants, a strategy that was not specific to detection and confirmation of the full mutational burden. Nonetheless, our negative findings are consistent with results from three recent studies that examined the patterns of de novo point mutations in ASDs by whole exome sequencing [37-39]. None of the three studies, all of which reported overlapping results with respect to genes conferring susceptibility to autism, identified the mTOR pathway genes that we investigated as genuine autism risk factors, though de novo mutations were identified in two of the genes, MYCBP2 and TSC2. Neale et al. [37] identified a single de novo missense mutation in the myc-binding domain of MYCBP2. The mutation was however predicted to be benign by PolyPhen-2. These findings do not rule out Pam (MYCBP2) as a functional participant in autism as it is probable that Pam, an E3 ubiquitin ligase, may be functioning only at the translational level as evidenced by recent work from our laboratory on mTORC1 regulation by Pam in the brain using mouse models [20]. Pam has been identified as a potential substrate whose phosphorylation is directly or indirectly controlled by mTORC1 in two independent phosphoproteome studies [40,41]. Furthermore, Pam has also been identified as a target transcript of fragile $\mathrm{X}$ mental retardation protein (FMRP) [42]. Both mTOR and FMRP 
Table 4 Inter-study comparison of TSC variants identified in ASD samples

\begin{tabular}{|c|c|c|c|c|c|}
\hline Gene & Amino acid position ${ }^{a}$ & Current study & Schaaf et al. [13] & Kelleher et al. [12] & Exome variant server \\
\hline TSC1 & P231L & - & - & ASD variant & - \\
\hline TSC1 & Q527R & - & - & ASD variant & - \\
\hline TSC1 & L116V & parental variant & control & ASD variant & reported $(0.0154)$ \\
\hline TSC1 & M322T & - & - & - & reported (16.5462) \\
\hline TSC1 & S334L & - & control & - & reported $(0.0308)$ \\
\hline TSC1 & R336W & - & control & ASD variant & reported $(0.0231)$ \\
\hline TSC1 & $\mathrm{T} 360 \mathrm{~N}$ & inherited variant & proband/control & - & reported $(0.0461)$ \\
\hline TSC1 & T3931 & - & - & ASD variant & reported $(0.0077)$ \\
\hline TSC1 & S403L & - & control & - & reported $(0.0615)$ \\
\hline TSC1 & P448S & inherited variant & proband & ASD variant & reported $(0.3844)$ \\
\hline TSC1 & G560S & - & control & - & - \\
\hline TSC1 & $\mathrm{K} 587 \mathrm{R}$ & - & proband/control & - & reported $(0.0923)$ \\
\hline TSC1 & Q654E & - & - & ASD variant & - \\
\hline TSC1 & $\mathrm{H} 732 \mathrm{Y}$ & - & proband/control & - & reported $(0.2691)$ \\
\hline TSC1 & N762S & - & proband & - & reported $(0.0384)$ \\
\hline TSC1 & Q906H & - & - & ASD variant & - \\
\hline TSC1 & G1035S & - & proband/control & - & reported $(0.1232)$ \\
\hline TSC1 & M1067L & - & proband & - & - \\
\hline TSC2 & $\mathrm{S} 6 \mathrm{~N}$ & - & control & - & - \\
\hline TSC2 & M50V & - & proband/control & - & reported $(0.0231)$ \\
\hline TSC2 & $164 \mathrm{~V}$ & inherited variant & yes & - & - \\
\hline TSC2 & E92V & - & control & - & reported $(0.1466)$ \\
\hline TSC2 & A97T & - & control & - & - \\
\hline TSC2 & A145T & - & - & ASD variant & - \\
\hline TSC2 & $\mathrm{H} 152 \mathrm{D}$ & inherited variant & - & - & - \\
\hline TSC2 & A431V & - & - & ASD variant & - \\
\hline TSC2 & A460T & - & proband/control & - & reported (0.0799) \\
\hline TSC2 & S487C & - & - & ASD variant & - \\
\hline TSC2 & K533Q & inherited variant & proband & - & - \\
\hline TSC2 & R537C & - & proband & - & reported $(0.0462)$ \\
\hline TSC2 & $1606 \mathrm{~V}$ & - & proband & - & reported $(0.0154)$ \\
\hline TSC2 & D635E & - & control & - & - \\
\hline TSC2 & V638M & - & - & ASD variant & - \\
\hline TSC2 & A678T & - & proband & - & reported $(0.0162)$ \\
\hline TSC2 & $\mathrm{Y} 719 \mathrm{H}$ & - & - & ASD variant & - \\
\hline TSC2 & $\mathrm{C} 728 \mathrm{~F}$ & parental variant & - & - & - \\
\hline TSC2 & P874L & - & - & ASD variant & reported $(0.0077)$ \\
\hline TSC2 & P878S & parental variant & - & - & - \\
\hline TSC2 & F904A & - & proband/control & - & reported $(0.0077)$ \\
\hline TSC2 & K954R & inherited variant & - & - & - \\
\hline TSC2 & S960F & parental variant & - & - & - \\
\hline TSC2 & E984Q & inherited variant & proband/control & - & - \\
\hline TSC2 & D1084E & - & - & ASD variant & - \\
\hline TSC2 & P1097L & - & proband & - & - \\
\hline TSC2 & A1141V & - & proband & - & reported (0.6389) \\
\hline TSC2 & $\mathrm{S} 1276 \mathrm{~F}$ & - & - & ASD variant & - \\
\hline TSC2 & P1305L & - & - & ASD variant & reported $(0.7186)$ \\
\hline
\end{tabular}


Table 4 Inter-study comparison of TSC variants identified in ASD samples (Continued)

\begin{tabular}{|c|c|c|c|c|c|}
\hline TSC2 & G1325D & - & - & ASD variant & - \\
\hline TSC2 & T1330M & parental variant & - & - & - \\
\hline TSC2 & E1351K & - & - & ASD variant & - \\
\hline TSC2 & S1365L & - & control & - & reported $(0.0077)$ \\
\hline TSC2 & R1369Q & - & proband & - & \\
\hline TSC2 & G1425R & - & proband & - & - \\
\hline TSC2 & A1429S & inherited variant & - & - & reported $(0.2324)$ \\
\hline TSC2 & G1439D & - & - & ASD variant & reported $(0.4412)$ \\
\hline TSC2 & S1448R & - & proband & - & - \\
\hline
\end{tabular}

play key roles in neuronal translation, and recent evidence indicates a link between mTORC1 signaling and FMRP. The role of Pam in regulating TSC/mTORC1 signaling in neurons, and more importantly the regulation of Pam by both mTORC1 and FMRP as well as the function of Pam in synapse development, suggest that either a direct or indirect involvement of this protein is possible in a subset of ASD.

Mutations in the TSC genes, TSC1 and TSC2 are known to cause syndromic autism [33]. In non-syndromic autism patients, TSC rates of $1.1 \%$ to $1.3 \%$ have been reported in many studies [43-47]. Two recent studies looked at the possible role of TSC1 and TSC 2 genes along with others in non-syndromic autism [12,13]. Schaaf et al. [13] introduced the concept of 'oligogenic heterozygosity' of coding non-synonymous variants as a novel pathogenic mechanism for ASD risk. The study suggested that groups of variants with smaller effects in multiple genes acting together might be contributing to autism in patients with near normal/normal IQs and non-syndromic autism. Since our study did not examine the other candidate genes included in that model, we believe that we can neither support nor refute the 'oligogenic heterozygosity' model. Kelleher et al. [12] found a significant excess of TSC gene single nucleotide variants in the AGRE (Autism Genetic Resource Exchange) samples compared to controls. Table 4 summarizes TSC variants identified by our study and those by Kelleher et al. [12] and Schaaf et al. [13]. Of the 20 TSC variants identified as ASD specific by Kelleher et al. [12], 7 variants (35\%) are reported in the NHLBI EVS (Table 4). Also, of the 12 variants identified as seen only in ASD probands and not controls by Schaaf et al. [13], 6 variants (50\%) are reported in the NHLBI EVS (Table 4), raising the question of whether these variants produce pathogenic effects. A damaging de novo mutation R1580W has been identified in the GAP-domain of TSC2 in one of the recent autism exome sequencing studies [39] raising the question as to whether a subclinical TSC was present in that patient. The functional impact of this variant however needs to be assessed.
Given that we have demonstrated our approach to be sensitive to detection of a single private mutation in each pool, our study has comparable or greater power to detect an association of similar effect size to those reported from de novo mutations in each of the previous exome studies (Neale et al., $\mathrm{n}=175$ trios [37]; O'Roak et al., $\mathrm{n}=209$ families [39]; Sanders et al., $\mathrm{n}=238$ families [38]). With 300 trios, we calculate that we have approximately $80 \%$ power to detect a scenario where $2.5 \%$ of cases are caused by rare variants in TSC1 and $4.2 \%$ of cases are caused by rare variants in TSC 2 at an experiment-wide significance threshold.

In our study, because we found a comparable number of transmitted and non-transmitted rare coding variants, we cannot provide support for an important role of rare variants in TSC genes in the pathogenesis of nonsyndromic autism. Exome sequencing data of 1,000 cases and matched controls from Neale and Daly laboratories have observed TSC1 missense variants that are predicted to be damaging by PolyPhen- 2 in 15 cases and 12 controls and a similar ratio of TSC2 missense variants in 63 cases and 60 controls (Daly M, unpublished data). This is consistent with our observation and those of previous exome sequencing studies that any ASD risk conferred by TSC gene variants is likely to be modest.

\section{Conclusions}

Our results suggest that in this sample of 300 trios ascertained, based on a proband with idiopathic ASD, there is no significant enrichment of ASD-risk variants in the candidate genes TSC1, TSC2, MYCBP2, RHEB and FBXO45. We did not observe any de novo or nonsense mutations with putative functional impact in any of the genes studied. Consistent with the null hypothesis, the number of rare missense variants transmitted to ASD cases was comparable to the untransmitted variants. Missense variants in TSC genes reported to have functional impact [30-32] are not observed in any of the idiopathic ASD cases [12,13,37-39] including those from our study and those in unpublished data from Neale and 
Daly. It remains essential to examine the functional impact of the missense variants detected in idiopathic ASD to conclude as to whether rare functional variants in TSC1/TSC2 could be a very rare cause of nonsyndromic autism. Our data do not necessarily undermine the potential functional role of mTORC1 signaling in ASD. It remains possible that genes associated with ASD will ultimately be linked directly or indirectly to this pathway, known for its complexity, with many feed-forward and feed-back regulatory features.

\section{Additional files}

Additional file 1: Table S1. Families from the Simons Simplex Collection used in the study. SSC family IDs for all the 300 ASD trios including affected probands and unaffected parents are provided.

Additional file 2: Figure S1. Schematic overview of the strategy used for next generation sequencing of candidate genes in the mTOR pathway. For the 300 ASD trios, DNA pooling was performed to prepare proband pools ( 10 pools of 30 samples each) and parental pools (10 pools of 60 samples each). The coding exons of the target genes were individually amplified using DNA pools followed by construction of libraries from PCR pools for deep resequencing on NGS platform Illumina GAll. From the identified variants, categories denoted by an asterisk $\left({ }^{*}\right)$ were chosen for confirmation by Sanger sequencing of the individual samples comprising the pool in which the variant was identified.

Additional file 3: Table S2. Primer sequences for PCR amplification of coding regions of five mTOR pathway genes.

Additional file 4: Table S3. Individual exon coverage data for each pool of samples.

Additional file 5: Table S4. Summary of reported missense variants in TSC genes.

\section{Abbreviations}

AGRE: Autism Genetic Resource Exchange; ASD: Autism spectrum disorder; Bp: Base pair; FMRP: Fragile X mental retardation protein; FXS: Fragile $X$ syndrome; LOVD: Leiden Open Variation Database; LTP: Long-term potentiation; mTOR: Mammalian target of rapamycin; mTORC1: Mammalian target of rapamycin complex 1; NF-1: Neurofibromatosis-1; NGS: Nextgenerating sequencing; NHLBI EVS: National Heart, Lung and Blood Institute exome variant server; NT: Neurotrophic; P: Phosphorylation; PCR: Polymerase chain reaction; Rc: Receptors; SFARI: Simons Foundation Autism Research Initiative; SSC: Simons Simplex Collection; TSC: Tuberous sclerosis complex; Ub: Ubiquitin.

\section{Competing interests}

The authors' declare they have no competing interests.

\section{Authors' contributions}

SB participated in study design, carried out the experiments, variant analyses and interpretation of data and drafted the manuscript. CC carried out nextgeneration sequence analysis. RLB assisted in study design and variant analyses. BMN, MJD and JFG provided inputs regarding study design, analysis and interpretation of data. MET participated in study design, nextgeneration sequencing analysis and its interpretation, and helped to draft the manuscript. VR contributed to overall planning, study design, interpretation of data and manuscript writing. All authors read and approved the final manuscript.

\section{Acknowledgements}

We sincerely thank all the families who have participated in the Simons Simplex study. We are grateful to Tammy Gillis and Mary Anne Anderson in the Center for Human Genetic Research Genomics Resource and Tissue Culture Facility for technical assistance. This work was supported by a grant from Simons Foundation for Autism Research Initiative (SFARI 95345 to VR),
National Institute of Health Grants NS024279 (to VR and JFG), MH095867 (to MET) and a fellowship from TS Alliance (to SB).

\section{Author details}

${ }^{1}$ Center for Human Genetic Research, Massachusetts General Hospital, Boston, MA 02114, USA. ${ }^{2}$ Analytical and Translational Genetics Unit, Massachusetts General Hospital, Boston, MA 02114, USA. ${ }^{3}$ Program in Medical and Population Genetics, Broad Institute, Cambridge, MA 02143, USA. ${ }^{4}$ Department of Genetics, Harvard Medical School, Boston, MA 02115, USA.

Received: 13 August 2012 Accepted: 5 March 2013

Published: 20 March 2013

\section{References}

1. Betancur C: Etiological heterogeneity in autism spectrum disorders: more than 100 genetic and genomic disorders and still counting. Brain Res 2011, 1380:42-77.

2. Bourgeron T: A synaptic trek to autism. Curr Opin Neurobiol 2009, 19:231-234.

3. Toro R, Konyukh M, Delorme R, Leblond C, Chaste P, Fauchereau F, Coleman M, Leboyer M, Gillberg C, Bourgeron T: Key role for gene dosage and synaptic homeostasis in autism spectrum disorders. Trends Genet 2010, 26:363-372

4. Cohen D, Pichard N, Tordjman S, Baumann C, Burglen L, Excoffier E, Lazar G, Mazet $P$, Pinquier $C$, Verloes $A$, Héron D: Specific genetic disorders and autism: clinical contribution towards their identification. J Autism Dev Disord 2005, 35:103-116.

5. Crino PB, Nathanson $\mathrm{KL}$, Henske EP: The tuberous sclerosis complex. N Engl J Med 2006, 355:1345-1356.

6. Han JM, Sahin M: TSC1/TSC2 signaling in the CNS. FEBS Lett 2011, 585:973-980.

7. Huang J, Manning BD: The TSC1-TSC2 complex: a molecular switchboard controlling cell growth. Biochem J 2008, 412:179-190.

8. Costa-Mattioli M, Sossin WS, Klann E, Sonenberg N: Translational control of long-lasting synaptic plasticity and memory. Neuron 2009, 61:10-26.

9. Hoeffer CA, Klann E: mTOR signaling: at the crossroads of plasticity, memory and disease. Trends Neurosci 2010, 33:67-75.

10. Tavazoie SF, Alvarez VA, Ridenour DA, Kwiatkowski DJ, Sabatini BL: Regulation of neuronal morphology and function by the tumor suppressors Tsc1 and Tsc2. Nat Neurosci 2005, 8:1727-1734.

11. Ehninger D, Han S, Shilyansky C, Zhou Y, Li W, Kwiatkowski DJ, Ramesh V, Silva AJ: Reversal of learning deficits in a Tsc2+/- mouse model of tuberous sclerosis. Nat Med 2008, 14:843-848.

12. Kelleher RJ III, Geigenmüller U, Hovhannisyan H, Trautman E, Pinard R, Rathmell B, Carpenter R, Margulies D: High-throughput sequencing of mGluR signaling pathway genes reveals enrichment of rare variants in autism. PLoS One 2012, 7:1-9.

13. Schaaf CP, Sabo A, Sakai Y, Crosby J, Muzny D, Hawes A, Lewis L, Akbar H, Varghese R, Boerwinkle E, Gibbs RA, Zoghbi HY: Oligogenic heterozygosity in individuals with high-functioning autism spectrum disorders. Hum Mol Genet 2011, 20:3366-3375.

14. Garami A, Zwartkruis FJ, Nobukuni T, Joaquin M, Roccio M, Stocker H, Kozma SC, Hafen E, Bos JL, Thomas G: Insulin activation of Rheb, a mediator of mTOR/S6K/4E-BP signaling, is inhibited by TSC1 and 2. Mol Cell 2003, 11:1457-1466.

15. Zhang Y, Gao X, Saucedo $\sqcup$, Ru B, Edgar BA, Pan D: Rheb is a direct target of the tuberous sclerosis tumour suppressor proteins. Nat Cell Biol 2003, 5:578-581.

16. Yamagata K, Sanders LK, Kaufmann WE, Yee W, Barnes CA, Nathans D, Worley PF: rheb, a growth factor- and synaptic activity-regulated gene, encodes a novel Ras-related protein. J Biol Chem 1994, 269:16333-16339.

17. Murthy V, Han S, Beauchamp RL, Smith N, Haddad LA, Ito N, Ramesh V: Pam and its ortholog highwire interact with and may negatively regulate the TSC1.TSC2 complex. J Biol Chem 2004, 279:1351-1358.

18. Po MD, Hwang C, Zheng M: PHRs: bridging axon guidance, outgrowth and synapse development. Curr Opin Neurobiol 2010, 20:100-107.

19. Han S, Witt RM, Santos TM, Polizzano C, Sabatini BL, Ramesh V: Pam (Protein associated with Myc) functions as an E3 ubiquitin ligase and regulates TSC/mTOR signaling. Cell Signal 2008, 20:1084-1091.

20. Han S, Kim S, Bahl S, Li L, Burande CF, Smith N, James M, Beauchamp RL, Bhide $P$, Diantonio A, Ramesh $V$ : The E3 ubiquitin ligase protein associated with Myc (Pam) regulates mammalian/mechanistic target of 
rapamycin complex 1 (mTORC1) signaling in vivo through $\mathrm{N}$ - and Cterminal domains. J Biol Chem 2012, 287:30063-30072.

21. Saiga T, Fukuda T, Matsumoto M, Tada H, Okano HJ, Okano H, Nakayama Kl: Fbxo45 forms a novel ubiquitin ligase complex and is required for neuronal development. Mol Cell Biol 2009, 29:3529-3543.

22. Fischbach GD, Lord C: The Simons Simplex Collection: a resource for identification of autism genetic risk factors. Neuron 2010, 68:192-195.

23. Rivas MA, Beaudoin M, Gardet A, Stevens C, Sharma Y, Zhang CK, Boucher G, Ripke S, Ellinghaus D, Burtt N, Fennell T, Kirby A, Latiano A, Goyette P, Green T, Halfvarson J, Haritunians T, Korn JM, Kuruvilla F, Lagacé C, Neale B, Lo KS, Schumm P, Törkvist L, National Institute of Diabetes and Digestive and Kidney Diseases, and Inflammatory Bowel Disease Genetics Consortium (NIDDK IBDGC), United Kingdom Inflammatory Bowel Disease Genetics Consortium, International Inflammatory Bowel Disease Genetics Consortium, Dubinsky MC, Brant SR, Silverberg MS, Duerr RH, et al: Deep resequencing of GWAS loci identifies independent rare variants associated with inflammatory bowel disease. Nat Genet 2011, 43:1066-1073.

24. Calvo SE, Tucker EJ, Compton AG, Kirby DM, Crawford G, Burtt NP, Rivas M, Guiducci C, Bruno DL, Goldberger OA, Redman MC, Wiltshire E, Wilson CJ, Altshuler D, Gabriel SB, Daly MJ, Thorburn DR, Mootha VK: Highthroughput, pooled sequencing identifies mutations in NUBPL and FOXRED1 in human complex I deficiency. Nat Genet 2010, 42:851-858.

25. McKenna A, Hanna M, Banks E, Sivachenko A, Cibulskis K, Kernytsky A, Garimella K, Altshuler D, Gabriel S, Daly M, DePristo MA: The genome analysis toolkit: a MapReduce framework for analyzing next-generation DNA sequencing data. Genome Res 2010, 20:1297-1303.

26. DePristo MA, Banks E, Poplin R, Garimella KV, Maguire JR, Hartl C, Philippakis AA, del Angel G, Rivas MA, Hanna M, McKenna A, Fennell TJ, Kernytsky AM, Sivachenko AY, Cibulskis K, Gabriel SB, Altshuler D, Daly MJ: A framework for variation discovery and genotyping using next-generation DNA sequencing data. Nat Genet 2011, 43:491-498.

27. Adzhubei IA, Schmidt S, Peshkin L, Ramensky VE, Gerasimova A, Bork P, Kondrashov AS, Sunyaev SR: A method and server for predicting damaging missense mutations. Nat Methods 2010, 7:248-249.

28. Desmet FO, Hamroun D, Lalande M, Collod-Béroud G, Claustres M, Béroud C: Human splicing finder: an online bioinformatics tool to predict splicing signals. Nucleic Acids Res 2009, 37:1-14.

29. Robinson JT, Thorvaldsdóttir H, Winckler W, Guttman M, Lander ES, Getz G, Mesirov JP: Integrative genomics viewer. Nat Biotechnol 2011, 29:24-26.

30. Hoogeveen-Westerveld M, Wentink M, van den Heuvel D, Mozaffari M, Ekong R, Povey S, den Dunnen JT, Metcalfe K, Vallee S, Krueger S, Bergoffen J, Shashi V, Elmslie F, Kwiatkowski D, Sampson J, Vidales C, Dzarir J, Garcia-Planells J, Dies K, Maat-Kievit A, van den Ouweland A, Halley D, Nellist M: Functional assessment of variants in the TSC1 and TSC2 genes identified in individuals with tuberous sclerosis complex. Hum Mutat 2011, 32:424-435.

31. Hoogeveen-Westerveld M, Ekong R, Povey S, Karbassi I, Batish SD, den Dunnen JT, van Eeghen A, Thiele E, Mayer K, Dies K, Wen L, Thompson C, Sparagana SP, Davies P, Aalfs C, van den Ouweland A, Halley D, Nellist M: Functional assessment of TSC1 missense variants identified in individuals with tuberous sclerosis complex. Hum Mutat 2012, 33:476-479.

32. Hoogeveen-Westerveld M, Ekong R, Povey S, Mayer K, Lannoy N, Elmslie F, Bebin M, Dies K, Thompson C, Sparagana SP, Davies P, van den Ouweland A, Halley D, Nellist M: Functional assessment of TSC2 variants identified in individuals with tuberous sclerosis complex. Hum Mutat 2013, 34:167-175.

33. Sahin M: Targeted treatment trials for tuberous sclerosis and autism: no longer a dream. Curr Opin Neurobiol 2012, 22:1-7.

34. Bloom AJ, Miller BR, Sanes JR, DiAntonio A: The requirement for Phr1 in CNS axon tract formation reveals the corticostriatal boundary as a choice point for cortical axons. Genes Dev 2007, 21:2593-2606.

35. Lewcock JW, Genoud N, Lettieri K, Pfaff SL: The ubiquitin ligase Phr1 regulates axon outgrowth through modulation of microtubule dynamics. Neuron 2007, 56:604-620

36. Nejentsev S, Walker N, Riches D, Egholm M, Todd JA: Rare variants of IFIH1, a gene implicated in antiviral responses, protect against type 1 diabetes. Science 2009, 324:387-389.

37. Neale BM, Kou Y, Liu L, Ma'ayan A, Samocha KE, Sabo A, Lin CF, Stevens C, Wang LS, Makarov V, Polak P, Yoon S, Maguire J, Crawford EL, Campbell NG, Geller ET, Valladares O, Schafer C, Liu H, Zhao T, Cai G, Lihm J, Dannenfelser R, Jabado O, Peralta Z, Nagaswamy U, Muzny D, Reid JG, Newsham I, Wu Y, et al: Patterns and rates of exonic de novo mutations in autism spectrum disorders. Nature 2012, 485:242-245.
38. Sanders SJ, Murtha MT, Gupta AR, Murdoch JD, Raubeson MJ, Willsey AJ, Ercan-Sencicek AG, DiLullo NM, Parikshak NN, Stein JL, Walker MF, Ober GT, Teran NA, Song Y, El-Fishawy P, Murtha RC, Choi M, Overton JD, Bjornson RD, Carriero NJ, Meyer KA, Bilguvar K, Mane SM, Sestan N, Lifton RP, Günel M, Roeder K, Geschwind DH, Devlin B, State MW: De novo mutations revealed by whole-exome sequencing are strongly associated with autism. Nature 2012, 485:237-241.

39. O'Roak BJ, Vives L, Girirajan S, Karakoc E, Krumm N, Coe BP, Levy R, Ko A, Lee C, Smith JD, Turner EH, Stanaway IB, Vernot B, Malig M, Baker C, Reilly B, Akey JM, Borenstein E, Rieder MJ, Nickerson DA, Bernier R, Shendure J, Eichler EE: Sporadic autism exomes reveal a highly interconnected protein network of de novo mutations. Nature 2012, 485:246-250.

40. Hsu PP, Kang SA, Rameseder J, Zhang Y, Ottina KA, Lim D, Peterson TR, Choi $Y$, Gray NS, Yaffe MB, Marto JA, Sabatini DM: The mTOR-regulated phosphoproteome reveals a mechanism of mTORC1-mediated inhibition of growth factor signaling. Science 2011, 332:1317-1322.

41. Yu Y, Yoon SO, Poulogiannis G, Yang Q, Ma XM, Villén J, Kubica N, Hoffman GR, Cantley LC, Gygi SP, Blenis J: Phosphoproteomic analysis identifies Grb10 as an mTORC1 substrate that negatively regulates insulin signaling. Science 2011, 332:1322-1326.

42. Darnell JC, Van Driesche SJ, Zhang C, Hung KY, Mele A, Fraser CE, Stone EF, Chen C, Fak JJ, Chi SW, Licatalosi DD, Richter JD, Darnell RB: FMRP stalls ribosomal translocation on mRNAs linked to synaptic function and autism. Cell 2011, 146:247-261.

43. Muhle R, Trentacoste SV, Rapin I: The genetics of autism. Pediatrics 2004 113:e472-486

44. Fombonne E, du Mazaubrun C: Prevalence of infantile autism in four French regions. Soc Psychiatry Psychiatr Epidemiol 1992, 27:203-210.

45. Fombonne E, Du Mazaubrun C, Cans C, Grandjean H: Autism and associated medical disorders in a French epidemiological survey. J Am Acad Child Adolesc Psychiatry 1997, 36:1561-1569.

46. Chakrabarti S, Fombonne E: Pervasive developmental disorders in preschool children. JAMA 2001, 285:3093-3099.

47. Chudley AE, Gutierrez E, Jocelyn LJ, Chodirker BN: Outcomes of genetic evaluation in children with pervasive developmental disorder. J Dev Behav Pediatr 1998, 19:321-325.

doi:10.1186/2040-2392-4-5

Cite this article as: Bahl et al.: Lack of association of rare functional variants in TSC1/TSC2 genes with autism spectrum disorder. Molecular Autism 2013 4:5.

\section{Submit your next manuscript to BioMed Central and take full advantage of:}

- Convenient online submission

- Thorough peer review

- No space constraints or color figure charges

- Immediate publication on acceptance

- Inclusion in PubMed, CAS, Scopus and Google Scholar

- Research which is freely available for redistribution 